\title{
Incidence and risk factors for post caesarean delivery surgical site infection in a tertiary care hospital
}

\author{
Smita S. Naik*, Ajit Nagarsenkar \\ Department of Obstetrics and Gynaecology, Goa Medical College, Bambolim, Goa, India
}

Received: 21 April 2021

Accepted: 12 May 2021

\section{*Correspondence:}

Dr. Smita S. Naik,

E-mail: smitanaik1708@gmail.com

Copyright: (c) the author(s), publisher and licensee Medip Academy. This is an open-access article distributed under the terms of the Creative Commons Attribution Non-Commercial License, which permits unrestricted non-commercial use, distribution, and reproduction in any medium, provided the original work is properly cited.

\begin{abstract}
Background: Post-operative surgical site infection (SSI) is the most commonly reported nosocomial infection which constitutes a major public health care problem worldwide. SSI are the one of the most common complication after caesarean section (C-sec) and results in maternal morbidity and mortality, increased length of the hospital stays and economic burden. The aim of the study is to determine the incidence and risk factors of SSI in women undergoing Csec.

Methods: The prospective observational study carried out in department of Obstetrics and Gynaecology in Goa medical college, Bambolim Goa from $1^{\text {st }}$ November 2017 to $30^{\text {th }}$ May 2019. Collection of data was carried using predesigned and pretested proforma. SSI was examined for association of different risk factors and its distribution.

Results: During this study period, 2106 patients underwent C-sec, out of which 103 patients developed post-operative SSI with the incidence rate being $4.89 \%$. The incidence rate was found higher in emergency cases $(6.55 \%)$ as compared to that of elective $(1.21 \%)$ and median time to SSI was the $6^{\text {th }}$ post- operative day. Majority of SSI, i.e., 102 out of 103 $(99.08 \%)$ were superficial SSI, $1(0.98 \%)$ were deep SSI and no organ/space SSI. The highest rate of SSI was found in 21-34 years of age group (84.47\%). The common risk factors associated are anaemia, diabetes, hypertension and obesity.

Conclusions: SSI results from multiple risk factors which include modifiable and non- modifiable factors and thorough analysis of these factors can help prevent SSI. The medical staff should focus on some of the modifiable risk factors can be eliminated by strict antisepsis, timely prophylactic antibiotic and maintaining normothermia as well as optimal glucose level.
\end{abstract}

Keywords: SSI, C-sec, Deep SSI, Superficial SSI

\section{INTRODUCTION}

Surgical site infections (SSI) are most common nosocomial infections and major cause of postoperative morbidity and sometimes mortality. ${ }^{1}$

Infections that occur in the wound created by an invasive procedure are generally referred to as SSI. SSIs are one of the most common causes of healthcare associated infections (HCAIs). SSIs are characterised by a breach of mechanical/anatomic defence mechanisms and are associated with greater morbidity, significant mortality, and increased cost of care. ${ }^{2}$

The SSI is defined by CDC (Centre for disease control and prevention) as an infection occurring within 30 days of surgery, in one of three locations: superficial, deep and/or spaces opened or manipulated during an operation. . $^{3,4}$

In India around $4.17 \%$ of the patients in surgical ward are at a risk of acquisition of infection and nosocomial infection. ${ }^{5}$ 
Of the $4.17 \%$ and $40 \%$ is postoperative surgical site infection, $42 \%$ associated with urinary infection, $14 \%$ is the respiratory infection, approximately $4 \%$ seen with sepsis and bacteremia. $^{6}$ Following caesarean most common post-operative infection are the surgical site infection, urinary tract infection and the infection of pelvic organs. ${ }^{7,8}$

Functional infection control committee should employ strict infection control policies which will significantly reduce SSI.

\section{METHODS}

The prospective observational study carried out in department of obstetrics and gynaecology in Goa medical college, Bambolim Goa, India from $1^{\text {st }}$ November 2017 to $30^{\text {th }}$ May 2019 after the approval of medical ethical committee. Qualitative data will be tested for significance using chi square test and continuous data will be tested for significance with two tailed $\mathrm{T}$ test with $\mathrm{p}$ value of $<0.05$ consider significant.

This is a descriptive study of all the patients who underwent $\mathrm{C}$-sec at our hospital. These patients were observed for the development of wound infections during their stay in the hospital. Those patients who developed surgical site infection that require wound dressing or wound re suturing were included in the study after informed consent. An elaborate study of these cases with regard to the date of admission, history, clinical features of wound infection, type of surgery, emergency or elective, preoperative and postoperative management is done till patient is discharged from hospital.

In history presenting complaints, duration, associated comorbid conditions, associated remote infections are noted.

If SSI was present, the type of SSI, according to the CDC criteria, date of onset, and the microorganism(s) cultured were reported. The treatment given was documented.

Wounds that were confined to the skin and subcutaneous tissues were classified as superficial. Presence of swelling, tenderness, obvious oozing of pus were the main determinants for inclusion in this category.

Abscesses were opened in the ward to give way for the pus under pressure, while pus swabs were taken for microbial sampling. All the patients with these wounds were not reoperated, but secondary repair was undertaken after control of sepsis. No report of mortality was observed from these groups of patients.

Deep surgical site infection was determined either through the ultrasonography, clinical signs of intra-abdominal sepsis.

\section{Inclusion criteria}

Inclusion criteria included all $\mathrm{C}$-sec done in tertiary care centre which undergo SSI, SSI occurring within 2 weeks of surgery.

\section{Exclusion criteria}

Exclusion criteria excluded patients not operated in GMC, patients coming with SSI after getting discharge from hospital, and patients already having pre-existing infection at the surgical site.

\section{RESULTS}

The current study was undertaken in Goa medical college in department of obstetrics and gynaecology from $1^{\text {st }}$ November 2017 to 30th May 2019 after the approval of medical ethical committee.

The study population consisted of underwent caesarean surgeries and were eligible considering the inclusion criteria. 103 patients out of 2,106 developed post-operative SSI and the overall rate being $4.89 \%$. The distribution of total number of post caesarean surgical site infection among the elective and emergency cases was $6.55 \%$ in the emergency group and $1.21 \%$ in the elective surgery group.

Superficial SSI accounted for $99.02 \%$ of the total cases and $0.98 \%$ were deep surgical site infection $<20$ years age group accounted for $3.88 \%$ of total cases of SSI, $84.47 \%$ of the patients were between $20-34$ years and $11.65 \%$ were in $>35$ years.

In our study, out of 103 cases of SSI, comorbidities were seen in 53 patients. Out of all patients with surgical site infection diabetes mellitus was seen in $18.44 \%$ of cases, anaemia in $20.39 \%$, and hypertension in $9.70 \%$ and obesity in $2.91 \%$.

As observed among 103 LSCS cases that had SSI, the risk of wound infection was $27.19 \%$ in patients who had rupture of membranes for more than 12 hours. Of all the patients with SSI, 35 patients with surgical site infection had undergone previous abdominal surgeries and contributed to $21.35 \%$.

Of all patients who had SSI, $87.38 \%$ patients had received spinal anaesthesia, followed by $12.62 \%$ of cases with general anaesthesia. 89 out of 103 cases received antibiotics 30 minutes before surgery with the incidence of $86.41 \%$ and $13.59 \%$ received during or after procedure. 92 $(89.32 \%)$ of the SSI diagnosed on $5-7^{\text {th }}$ post-operative day, $5(4.85 \%)$ SSI were diagnosed <5 days and $6(5.82 \%)$ cases diagnosed after 7 days.

Out of all patients with surgical site infection, 71 patients $(68.93 \%)$ underwent wound re-suturing and remaining 32 $(31.07 \%)$ cases healed by wound dressing. 
Table 1: Distribution of different type of C-sec.

\begin{tabular}{|c|c|c|c|c|}
\hline \multirow{2}{*}{ Type of C-sec } & \multicolumn{2}{|c|}{ Surgical site infection } & \multirow{2}{*}{ Total } & \multirow{2}{*}{ Percentage (\%) } \\
\hline & Yes & No & & \\
\hline Elective & 8 & 648 & 656 & 1.21 \\
\hline Emergency & 95 & 1355 & 1450 & 6.55 \\
\hline Total & 103 & 2003 & 2106 & \\
\hline
\end{tabular}

Table 2: Distribution of SSI based on risk factors involved.

\begin{tabular}{|c|c|c|c|}
\hline Variables & Groups & SSI & Percentage $(\%)$ \\
\hline \multirow{2}{*}{ Type of LSCS } & Superficial SSI & 102 & 99.02 \\
\hline & Deep SSI & 1 & 0.98 \\
\hline \multirow{3}{*}{ Age group (Year) } & $<20$ & 4 & 3.88 \\
\hline & $21-34$ & 87 & 84.47 \\
\hline & $>35$ & 12 & 11.65 \\
\hline \multirow{4}{*}{ Comorbidities } & Anaemia & 21 & 20.39 \\
\hline & Diabetes & 19 & 18.44 \\
\hline & Hypertension & 10 & 9.70 \\
\hline & Obesity & 3 & 2.91 \\
\hline \multirow{2}{*}{$\begin{array}{l}\text { Prolonged rupture of membranes } \\
\text { (hourly) }\end{array}$} & $<12$ & 75 & 72.81 \\
\hline & $>12$ & 23 & 271 \\
\hline \multirow{2}{*}{ Previous 1 or more LSCS } & Yes & 22 & 21.35 \\
\hline & No & 81 & 78.64 \\
\hline \multirow{2}{*}{ Type of anaesthesia } & Regional & 13 & 12.62 \\
\hline & General & 90 & 87.38 \\
\hline \multirow{2}{*}{ Time of prophylactic antibiotic } & 30 minutes prior to surgery & 14 & 13.59 \\
\hline & With/after the surgery & 89 & 86.41 \\
\hline \multirow{3}{*}{ Day of diagnosis of SSI (Days) } & $<5$ & 5 & 4.85 \\
\hline & $5-7$ & 92 & 89.32 \\
\hline & $>7$ & 6 & 5.82 \\
\hline \multirow{2}{*}{ Management of SSI } & Conservative & 32 & 31.07 \\
\hline & Wound re suturing & 71 & 68.93 \\
\hline
\end{tabular}

\section{DISCUSSION}

The study conducted in the only referral tertiary care hospital in Goa over the period of 18 months based on the inclusion criteria; total 2,106 patients who underwent $\mathrm{C}$ sec were eligible for analysis in Goa medical college in obstetrics and gynaecology department. The present study showed the postoperative SSI was found in 103 patients out of 2,106 amounting for incidence of $4.89 \%$ which is comparable to Bizimana et al $4.9 \%$ and Damecha et al being $4.25 \% .^{9,10}$

Incidence of postoperative SSI was more in emergency Csec than elective surgeries (6.55\% vs $1.21 \%)$. The similar results were observed in Bizimana et al study, which reported $3.4 \%$ in emergency surgeries and $1.5 \%$ in elective surgeries. ${ }^{9}$ In our study we found that incidence of infection is higher in emergency cases as compared to routine elective cases. The probable reason being the elective cases are better prepared. Most of the emergency cases are done at the trainee level. Hence longer period of time taken for surgery and with the possibility of higher blood loss in emergency cases compared to elective cases which are handled by the consultant. Ours being the only tertiary level postgraduate teaching institute in Goa these is an unavoidable parameter.

Superficial SSI was accounted for $99.2 \%$ cases of total cases and $0.8 \%$. However, in other studies the rate of deep SSI and organ space SSI was more i.e., in Mpogoro et al study $12.5 \%$ was deep/organ space SSI and in Bizimana et al study $4.9 \%$ was deep SSI and $2.5 \%$ was organ space SSI. ${ }^{9,11}$ Most probable reason for this difference could be early diagnosis and timely antibiotic received according to sensitivity pattern on culture report.

Considering the age group, 26-30 years accounted for $37.8 \%$ of total cases of surgical site infection, $23.6 \%$ of patients were between 21-25 years and $17.3 \%$ belonged to 31-35 years. Mamo et al reported $13.9 \%$ of SSI in <19 years age group patients, $63.9 \%$ in $20-34$ years and $22.2 \%$ in $\geq 35$ years. $^{12}$

In our study the majority of patients i.e., $63 \%$ had SSI had comorbid conditions. Among this, it was seen that diabetes mellitus was present in $30 \%$ cases followed by anaemia in $21 \%$ cases. The most common risk factors in postoperative SSI reported in Bhaduria et al study was anemia (21.15\%) 
and diabetes $8.45 \% .{ }^{13}$ The most probable reason being presence of multiple comorbidities like anaemia and diabetes in India. In addition to this diabetes also results in hyperglycaemia which further results in abnormal cell mediated immunity and phagocytosis and reduction in blood supply to tissues.

As observed among 103 LSCS cases that had SSI, the risk of wound infection was $27.19 \%$ in patients who had rupture of bag of membranes for more than 12 hours, however in Bhaduria et al study incidence of SSI with prolonged rupture of membranes $23.05 \%$. In pregnancy cervical mucus and amniotic fluid act as a barrier to infection. However, in case of prolonged rupture of membranes, the protective effect wanes off as amniotic fluid no longer remains sterile. Once amniotic fluid gets infected, it might act as a transport medium through which microorganisms comes in contact with uterus and skin incision site.

Of all the patients with SSI, 35 patients had previous abdominal surgeries and contributed to $27.6 \%$ and which was comparable to Naphade et al study which accounted to $26 \%$ of surgical site infection in previous abdominal surgeries. ${ }^{14}$

In our study, SSI was seen majority in Pfannenstiel incision accounting for $88.2 \%$ as compared to $11.8 \%$ with vertical incision, most probably because most of the cases with SSI were LSCS cases same seen in comparison with Mamo et al study wherein SSI were observed in $83.3 \%$ with Pfannenstiel incision and $16.7 \%$ with vertical incision. $^{12}$

121 out of 127 cases received pre op antibiotics before 1 hour of surgery with the incidence of $95.3 \%$. In Pathak et al study inappropriate timing of antibiotic prophylaxis was a significant risk factor for SSI and during the study period no standard policy for prophylaxis was followed.

Most of the wound infections diagnosed on $5-7^{\text {th }}$ postoperative day with peak on $6^{\text {th }}$ day with 48 cases $(37.8 \%)$ which indicates source of infection is not due to surgical procedure but due to external environment or patient's attendant. Naphade et al reported most of the wound infections diagnosed on $5-7^{\text {th }}$ post-operative day with peak on $6^{\text {th }}$ day with 48 cases $(37.8 \%){ }^{14}$

In our study, 71 patients $(68.93 \%)$ underwent wound resuturing (surgical management) and remaining 32 $(31.07 \%)$ cases healed by wound dressing (conservative management). Wound re-suturing was achieved after obtaining wound swab culture report, starting sensitive antibiotic and then carrying out secondary suturing by excising fibrosed granulation tissue and refreshing the edges. Naphade et al study reported $29 \%$ had their wound healed by wound dressing (secondary intention) whereas $71 \%$ needed secondary suturing. ${ }^{14}$

\section{CONCLUSION}

In the current scenario, the increasing trend of SSI is seen mostly due to increase in the number of surgeries which are performed. In the preoperative period SSI can be prevented by identifying SSI at early stages, proper preoperative workup of patient, correction of anemia, blood sugar level. These little efforts can significantly reduce the burden on the patient and the surgeons and further reduce morbidity and mortality. This will also ensure reduction in hospital stay and economical load on patient. The surgeon should consider proper surgical technique during the surgery and preoperative prophylactic antibiotics should be started to patients. Knowledge of the independent risk factors for SSI is very important to develop strategies to reduce incidence of SSI and to identify high risk patients require intensive postoperative surveillance.

Funding: No funding sources Conflict of interest: None declared

Ethical approval: The study was approved by the Institutional Ethics Committee

\section{REFERENCES}

1. Ferroz EM, Bacelar TS, Aguiar JLA, Ferraz AAB, Pognossin G, Batista JEM. Wound infections rates in clean surgery. Inf contr Hosp epidem, 1999;13:45762.

2. Leaper DJ. Surgical infection. Bailey and Love's short practice of surgery $25^{\text {th }}$ edition. 2004;32-48.

3. World Health Organisation. Global guidelines of prevention of surgical site infection. 2016. Available at: http//www.who.int/gpsc/global-guidelinesweb.pdf.

4. Black JD, De Haydu C, Fan L, Sheth SS. Surgical site infection in gynaecology. Obstet Gynecol Surv. 2014;69(8):501-10.

5. Shah F, Gandhi M, Mehta V, Udani D, Mundra M. Nosocomial Infections in Surgical Wards. Internet $\mathbf{J}$ Surg. 2009;24:1.

6. Mandell GL, Bennett JE, Dolin R. Practice of Prevention of Postoperative Infection. In: Mandell, Bennett, and Dolin: Principles and Practice of Infectious Diseases (6thedtn), Churchill Livingstone, Elsevier, Florida, USA. 2005;3540-5.

7. Smaill FM, Gyte GML. Antibiotic prophylaxis versus no prophylaxis for preventing infection after caesarean section. Cochrane Database Syst Rev. 2010;CD007482.

8. Smaill FM, Hofmeyr GJ. Antibiotic prophylaxis for caesarean section. Cochrane Database Syst Rev. 2002;CD000933.

9. Bizimana JB, Ndoli J, Bayingana C, Baluhe I, Gilson GJ, Habimana E. Prevalence and risk factors for post caesarean delivery surgical site infection in a teaching hospital setting in rural Rwanda. Int J Curr Microbiol appl sci. 2016:5(6):631-41. 
10. Dhamecha M, Chauhan N, Kavathia G, Goswami Y, Gosai K. Incidence and predictors of surgical site infection, a study at tertiary care hospital. GCSMC J Med Sci. 2014;3.

11. Mpogoro FJ, Mshana SF, Mirambo MM, Kidenya BR, Gumodoka B, Imirzalioglu C. Incidence and predictors of surgical site infections following caesarean section at Bugando Medical centre, Mwanza, Tanzania. Antimicrobial resistance infect control. 2014;3:25.

12. Mamo T, Abebe TW, Chichiabellu TY, Anjulo AA. Risk factors for surgical site infections in obstetrics: a retrospective study in an Ethiopian referral hospital. Patient Safety Surg. 2017;11:24.
13. Bhadaura AR. Clinical study of post-operative wound infection in obstetric and gynaecological surgeries in a tertiary care set up. Int J Reprod Contracept obstret Gynecol. 2013;2,631-8.

14. Naphade SA. Study of Surgical Site Infections following Gynaecological Surgeries in a Tertiary Care Hospital; MVP. J Med Sci. 2017;4(2):186-92.

15. Pathak A, Mahadik K, Swami MB, Roy PK, Sharma $\mathrm{M}$, Mahadik VK et al. Incidence and risk factors for surgical site infections in obstetric and gynecological surgeries from a teaching hospital in rural India. Antimicrobial Resistance Infect Control. 2017;6:66.

Cite this article as: Naik SS, Nagarsenkar A.

Incidence and risk factors for post caesarean delivery surgical site infection in a tertiary care hospital. Int $\mathbf{J}$ Reprod Contracept Obstet Gynecol 2021;10:2316-20. 